\title{
LA EDUCACIÓN INTERCULTURAL EN AMÉRICA LATINA Y EL CARIBE COMO MEDIO PARA LA INCLUSIÓN EN LA ESCUELA: ESTUDIO DE CASO EN ESTABLECIMIENTOS EDUCATIVOS EN LA CIUDAD DE BOGOTÁ, COLOMBIA
}

Gilma Rosa Sanabria León ${ }^{1}$

\section{Introducción}

El siglo XXI se ha caracterizado por la globalización del conocimiento y la cultura, el fácil acceso a los saberes y el intercambio cultural en todas las regiones del mundo a través de los procesos de inmigración y emigración. Hoy no se puede hablar de una nación netamente pura o de una cultura autóctona, porque la sociedad está conformada por individuos de diferentes procedencias, con múltiples tradiciones que enriquecen y transforman la cultura.

América Latina está compuesta por la riqueza multicultural de sus habitantes; sin embargo, desde la época colonial el mestizaje y la diversidad cultural no fueron sinónimos

1 Doctora en Educación de la UNED, Madrid, España. Posdoctora en Narrativa y Ciencia de la Universidad Santo Tomás, Bogotá. Docente e investigadora universitaria. Coordinadora de Procesos de Acreditación. Jefe de la Oficina de Planeación Universitaria. Directora del Centro de Investigación VUAD de la Universidad Santo Tomás, Bogotá. Autora de libros, capítulos de libros y textos universitarios. Asesora y consultora para la creación de Programas Universitarios. Email: gilma_65@yahoo.com. 
de riqueza, por el contrario, su significación y representación social fue asumida desde la inferioridad por parte del dominio de las élites intercontinentales, que se asumían desde una identidad particularmente enriquecida y privilegiada.

Como efecto de dicho proceso histórico, en la sociedad actual se acuñan términos como equidad, democracia, ciudadanía, pluriculturalidad, entre otros, para garantizar, al menos en la teoría, la igualdad entre todos sus miembros, las mismas oportunidades de acceso en todos los niveles y los derechos y beneficios sociales, sin importar la diversidad. Al respecto, González J.E. (2007) afirma que la evidencia histórica que muestra la existencia de la diversidad, tanto al interior de las naciones como en el concierto de naciones del mundo, constituye una fuente de interpelación para las concepciones teóricas acerca de la democracia, en lo que respecta a su capacidad para reconocer la diversidad, respetarla e incorporarla al ejercicio de los derechos civiles y políticos.

En esta línea, tanto el ejercicio de la democracia, como la garantía de un desarrollo equitativo para todos los sujetos que hacen parte de un mismo territorio, es una problemática que las sociedades de hoy en día siguen debatiendo, ya que la diversidad ha sido asumida bajo discursos hegemónicos que posicionan a los sujetos bajo una falsa ilusión de igualdad, donde unos están más capacitados o tienen más accesos y derechos que otros, lo cual representa un gran obstáculo para el bienestar de las naciones multiculturales. Esta situación genera conflictos entre los grupos concebidos como minoritarios (los cuales realmente tienen esta denominación en cuanto son menores en derechos y reconocimiento), y mayoritarios, quienes ejercen el poder, lo que sigue manteniendo el statu quo de la desigualdad y exclusión. Cuando se asume que la población tiene las mismas costumbres, los mismos ancestros y que todos tendrían unas metas comunes, se está negando la posibilidad de la diferencia y ello afecta todas las estructuras de las sociedades.

Por lo tanto, las sociedades deben ser cada vez más equitativas e incluyentes, y un aspecto fundamental es la relación entre sociedades y educación porque las escuelas como centros de formación y socialización de los ciudadanos se vuelven escenarios fundamentales para prevenir y afrontar las formas de discriminación y exclusión de los sujetos. Debido a esto, es fundamental cuestionarse sobre cómo la educación puede ayudar a la construcción de sociedades incluyentes; esta preocupación debe estar presente por un lado en las familias y, por el otro, en el compromiso político y ético de los gobernantes frente a la formulación de las políticas públicas que orientan los objetivos del sistema educativo, el cual debe contar con las estrategias para abordar la diversidad de necesidades, capacidades, preferencias y culturas que son parte de las sociedades. 
Frente a la anterior realidad surge la pregunta: ¿Qué factores inciden en la exclusión de afrodescendientes, indígenas y comunidad LGBTI² en la escuela? Porque, si bien es cierto que el sistema educativo en Colombia contempla, desde la normatividad, la posibilidad de erradicar las formas de discriminación y exclusión de determinados grupos sociales, en contextos reales no se implementa dicha legislación, razón por la que se consideró como objetivo general de esta investigación determinar los posibles factores que inciden en la exclusión de afrodescendientes, indígenas y comunidad LGBTI en la escuela. Para ello fue de vital importancia conocer las percepciones de los docentes como actores protagónicos en la labor pedagógica, asimismo cobraron relevancia los estudios de los organismos multilaterales frente al tema en mención.

En relación a los docentes, fueron fundamentales sus percepciones frente a las estrategias de inclusión, ya que sus opiniones son clave para el éxito de las mismas (Díaz y Franco, 2010). Por lo anterior, mediante la realización de una encuesta, se buscó reconocer dichas percepciones sobre el rol tanto de la escuela como de los maestros, desde el ejercicio de la profesión, en relación al manejo de la diversidad cultural y sexual en las aulas. Este ejercicio condujo a la determinación de las posibles causas que afectan la situación de grupos socialmente excluidos como los afrodescendientes ${ }^{3}$, los indígenas y la comunidad LGBTI, bajo el modelo educativo actual, por lo que se rescata y se acude a la propuesta de la educación intercultural como estrategia para enfrentar esta problemática.

\section{Antecedentes del problema de investigación}

\section{Educación intercultural: procesos en América Latina y el Caribe}

La interculturalidad ha sido un tema abordado en América Latina y el Caribe desde los años setenta; la academia, el campo político, los movimientos sociales, entre otros, son algunos de los principales actores que se han planteado una discusión al respecto, ya que para dar

2 Lesbianas, Gays, Bisexuales, Transexuales/Transgeneristas, Intersexuales.

3 En Colombia y para este estudio el término afrodescendiente engloba a la población con antepasados oriundos de África. 
atención y respuesta a la diversidad cultural de la región se ha promovido la propuesta intercultural como una estrategia pertinente y adecuada para enfrentar las problemáticas de desigualdad, discriminación y exclusión, presentes en las sociedades.

La multiculturalidad posee varias dimensiones: «política, ética, social, jurídica, epistemológica y educacional» (Ferrão Candau, 2010, p. 334); cada una de ellas se ha venido discutiendo por diferentes autores y sigue siendo parte de nuevas propuestas y estrategias para llevar a la realidad el reconocimiento del mundo diverso. Cuando se acepta y se toma conciencia de que las sociedades no son un cúmulo de seres con identidades homogéneas, se inicia la discusión sobre cómo abordar y tratar de manera justa las nuevas relaciones que se derivan del encuentro entre sujetos con intereses, necesidades y procedencias diferentes. Es por ello que la interculturalidad, entendida como el diálogo entre culturas, hace parte de un debate actual y necesario para abordar las realidades de las sociedades; es importante aclarar que este es un proyecto en construcción y en esa medida es difícil hablar de sociedades que ya sean interculturales, pues llevar a cabo el diálogo entre culturas y sujetos diversos sigue siendo un proceso complejo y problemático pero necesario.

No obstante, al hacer una revisión en el proceso de consolidación del proyecto intercultural, es importante mencionar los esfuerzos en un primer momento de las comunidades indígenas de Latinoamérica para realizar un llamado a su visibilización y participación en el modelo de enseñanza tradicional. En el caso colombiano, los años setenta fueron momentos de lucha liderados por los pueblos indígenas, donde las movilizaciones eran motivadas por el reclamo a una educación acorde a su cultura, sus necesidades y proyectos de vida (Rojas, 2008); la presión ejercida por las comunidades permitió ir consolidando lo que se ha empezado a denominar proyecto etnoeducativo.

Teniendo en cuenta lo anterior, es importante destacar que la presencia de la población indígena en América Latina y el Caribe es considerable, de allí la importancia de los aportes que estos han realizado a la propuesta de una educación que contemple la diversidad cultural. Según el Siteal4 (2012):

La población indígena en América Latina y el Caribe oscila entre los 40 y 50 millones. La estimación censal realizada a partir de la ronda 2000 , ubica el umbral en los 30 millones (CEPAL, 2006). Algunos autores indican que la población indígena conforma 410 grupos

4 Sistema de Información de Tendencias Educativas en América Latina. 
étnicos (Hopenhayn, cca. 2005), otros que superan los 500 (UNICEF - FUNPROEIB Andes, 2009) y por último, otras fuentes indican que en la actualidad hay más de 640 pueblos reconocidos por los diferentes estados latinoamericanos (CEPAL, 2006). En relación a la distribución espacial, partiendo de la información censal disponible, se observa que Perú es el país que reúne la mayor cantidad de población indígena ( 8,5 millones), seguido por México (6,1 millones), el Estado Plurinacional de Bolivia (5 millones) y Guatemala (4,6 millones). Por su parte, Brasil, Colombia, Chile, Ecuador y la República Bolivariana de Venezuela, integran un grupo de países donde el número de indígenas fluctúa alrededor de medio millón o un millón de personas. Luego se identifica otro grupo de países, constituido por Argentina, Costa Rica, El Salvador, Honduras, Nicaragua, Panamá, Paraguay y Uruguay, en el cual la población indígena no supera a las 500 mil personas. Por último, se advierte que la población indígena de Cuba, Haití y República Dominicana ha sido prácticamente exterminada (CEPAL, 2006). Si se analiza el peso relativo de la población indígena sobre el total nacional, sobresalen el Estado Plurinacional de Bolivia (62\%), Guatemala (41 \%) y Perú (32\%). Luego, Chile, Ecuador, Honduras, México, Nicaragua y Panamá constituyen otro grupo de países donde el peso relativo de la población indígena oscila entre el $5 \%$ y el $10 \%$ (CEPAL, 2006) (p.3).

En efecto, los proyectos educativos de las comunidades indígenas son trascendentales y significativos en la región, siendo ellos los que han dado los primeros pasos en pro de la búsqueda de la interculturalidad, partiendo de estrategias como la propuesta del bilingüismo como un medio para afectar los modelos de enseñanza tradicional; sin embargo, estos enfoques también han sido empleados bajo la tendencia de la asimilación cultural, la alfabetización y la inclusión negativa de los pueblos indígenas (Ferrão Candau, 2010), lo que afecta el objetivo central de establecer un diálogo equitativo entre diversas culturas.

Sin embargo, lo más importante es el reconocimiento de las luchas y aportes de las comunidades indígenas, porque es a partir de esta situación que otros grupos sociales empiezan a participar y debatir en la región frente a la discusión de una educación que supere el etnocentrismo, la desigualdad y la discriminación, mediante el reconocimiento de otras cosmovisiones y prácticas que son valiosas dentro de la conformación de las sociedades multiculturales. De allí la importancia de otros trabajos como los de las comunidades negras, los cuales se vuelven también actores protagónicos en este proceso.

La población negra en Latinoamérica es heterogénea debido a los procesos de colonización que sufrió la región, y son precisamente estos procesos históricos los que 
hoy en día siguen afectando a esta población de manera negativa. En países como Brasil, es hasta finales del siglo XIX que la esclavitud logra superarse (Ferrão Candau, 2010), lo que evidencia cómo la situación de discriminación y desigualdad ha afectado grave y constantemente a las poblaciones afrodescendientes, poniendo en discusión los derechos que poseen como ciudadanos y seres humanos.

Por su parte, el estudio del Siteal (2012) señala respecto a los porcentajes y presencia de la población negra en Latinoamérica lo siguiente:

De acuerdo a las estimaciones realizadas por investigadores de la CEPAL, en la región latinoamericana la población negra y mestiza, afrolatina y afrocaribeña, supera a los 150 millones de personas, esto es, alrededor de un 30 \% de la población total de la región. Al estudiar su distribución, Brasil se presenta como el país que condensa una mayor proporción de población afrodescendiente, seguido por Colombia y luego por la República Bolivariana de Venezuela, según Bello y Rangel (2002). Los mismos autores precisan que la población mestiza y negra de Brasil asciende a más de 74 millones de personas, mientras en Colombia supera los 31 millones; en Venezuela, los 17 millones; en República Dominicana se aproxima a los 7 millones de personas y, en Cuba, ronda los 3,7 millones. La población afrodescendiente de Ecuador representa al $5 \%$ de la población total, mientras que en Costa Rica este valor disminuye al $2 \%$ y en Honduras, al $1 \%$. Nuevamente, se registran diferencias considerables dependiendo de cuáles sean las fuentes consultadas. La población afrodescendiente en Cuba, donde se llega a variaciones de más de 28 puntos porcentuales entre fuentes, y también en Nicaragua, donde de valores inferiores al $1 \%$ se pasa a estimaciones que rondan el $9 \%$ de la población total (p. 4).

Lo anterior indica que los datos estadísticos difieren en relación a la fuente; sin embargo no se puede negar la considerable presencia tanto de grupos indígenas como de afrodescendientes en Latinoamérica y el Caribe. Colombia, como segundo país en el continente con mayor población afrodescendiente, presenció en los años ochenta las luchas de las comunidades negras, donde las peticiones y demandas giraban en torno al reconocimiento y garantía de sus derechos acorde a sus particularidades étnicas, pero también como miembros del conjunto nacional, es decir, haciendo valer sus derechos como ciudadanos.

En Colombia, como reflejo de las luchas de los grupos citados anteriormente, se consolidan leyes como la Ley 70 de 1993 que en el art. 39 manifiesta la importancia de un 
sistema educativo que reconozca la prácticas culturales y la historia de estas comunidades, también se logra en la Ley 115 de 1994 art. 35 establecer la definición de etnoeducación como estrategia para la enseñanza y valoración de las particularidades socioculturales tanto de pueblos indígenas como de pueblos afrodescendientes. Estos son logros que a nivel nacional se alcanzan como producto de las luchas y reclamos por parte de los grupos marginados, frente a un sistema escolar que reduce la diversidad a la uniformidad cultural y que desconoce la multiplicidad de identidades culturales y expresiones de las mismas.

A pesar de todo, tanto grupos indígenas como afroamericanos han luchado por posicionar sus proyectos educativos y la necesidad de incluir en estos las cosmovisiones y experiencias propias de su cultura; sin embargo, la responsabilidad que le corresponde al Estado, como garante de los derechos de sus ciudadanos, se ha manifestado con la construcción de políticas focalizadas que siguen interpretando la diversidad como sinónimo de inferioridad. Si bien estos grupos han sido marginados cultural, social y económicamente, se deben romper esos esquemas de pobreza y marginación mediante políticas de largo plazo que contemplen las diversas propuestas de desarrollo que estos grupos puedan aportar a la sociedad; esto se logrará fundamentalmente a través de la educación, donde la escuela juega un papel preponderante para hacer realidad las políticas que se quedan en su formulación.

Por otra parte, la situación de focalización bajo la noción de asimetrías y desigualdad se evidencia a lo largo de Latinoamérica donde los proyectos educativos para grupos étnicos son ubicados en zonas rurales, desconociendo los procesos migratorios y la significativa presencia de indígenas y afroamericanos en territorios como la ciudad (Hirmas Ready, 2009); de allí que la educación intercultural no deba ser solo un trabajo de los grupos considerados excluidos y marginados, los grupos mayoritarios y que ejercen la discriminación también deben ser un sector que intervenga y que sea intervenido.

De hecho, el informe de la Unesco sobre la educación en América Latina (2012) muestra cómo los gobiernos latinoamericanos tienen debilidades significativas en aspectos como el acceso, la calidad y la pertinencia de la educación. Al hablar de educación intercultural, el informe señala que pese a los logros normativos llevados acabo por organismos internacionales como la Unesco con la Declaración Universal sobre la Diversidad Cultural (2002), el Convenio n. ${ }^{0} 169$ de la OIT o la Convención de los Derechos de los Niños de la Unicef, «incorporar estas orientaciones en el campo de la educación en la región no ha sido fácil.[...] La construcción de interculturalidad en América Latina y el Caribe no está exenta de los conflictos y tensiones que suponen esta diversidad, debido a las situaciones de 
inequidad generalizada» (p. 106). Por lo tanto, la incidencia de la educación intercultural va más allá de la pura dimensión étnica, también corresponde a una mejora en la calidad de vida de las sociedades, en términos de equidad y justicia social.

Los informes estadísticos y discusiones, mencionados anteriormente, están presentes en Latinoamérica y el Caribe en los debates sobre multiculturalidad, así como en la realidad colombiana; como se señaló previamente, los indígenas y afrodescendientes han sido líderes en el proceso de una aproximación a la construcción de un sistema educativo incluyente y justo respecto al trato a la diversidad. Logros como la cátedra de Estudios Afrocolombianos desde la Ley 7o, apoyada por el Decreto 1122 de 1998 que establece su carácter obligatorio en las instituciones educativas, o la Escuela Normal Indígena de Uribia en la Guajira (Hirmas Ready, 2009), evidencian la necesidad de ver la interculturalidad como estrategia que permita superar las divisiones dadas por la universalidad y la homogenización de la cultura. La búsqueda del consenso, del reconocimiento, de la inclusión y del diálogo en las escuelas, permite la construcción de nuevas relaciones sociales más justas y equitativas.

En el caso colombiano, Castro (2009) hace una revisión sobre los estudios interculturales llevados a cabo en el país señalando autores como:

- Artunduaga (1997), que con sus estudios de etnoeducación plantea la propuesta del reconocimiento por parte del Estado para los grupos minoritarios como agentes protagónicos en la construcción de diálogos que aporten a cada cultura.

- Enciso (2004) quien, junto con el Ministerio de Educación Nacional, hace un análisis sobre los avances de la etnoeducación a nivel nacional, evidenciando un aumento en las experiencias escolares de los grupos étnicos y señalando también el déficit de material pedagógico para la continuidad, extensión y desarrollo de dichos procesos, así como la escases de diagnósticos y evaluaciones que imposibilitan la retroalimentación y avance de nuevas propuestas pedagógicas en pro de la diversidad.

- Restrepo y Rojas (2005), analizan la situación de las comunidades negras y cómo las dinámicas de discriminación e invisibilización en la escuela siguen siendo un obstáculo para transformar las políticas de representación de los grupos afrodescendientes.

Los investigadores citados anteriormente (entre otros igual de importantes) y los académicos reconocen la importancia y la pertinencia de abordar la diversidad cultural desde la interculturalidad en las escuelas del país, ya que con la declaración de la multiculturalidad y plurietnicidad en la Constitución del 91, se hace necesario fortalecer 
más allá de la legislación la consecución de la inclusión y, lo más importante, el diálogo desde la diversidad. Los estudios realizados demuestran la necesidad de currículos incluyentes y novedosos, de docentes adecuadamente formados para el diálogo intercultural y la participación activa de las comunidades que han sido marginadas a través de la historia; si bien la dimensión étnica es fundamental en el proceso intercultural, la cultura y la diversidad no solo parten de allí, el género, la clase social y la sexualidad son aspectos que forman parte de la propuesta de una educación incluyente y participativa.

\section{Problema de investigación}

Esta investigación hace un llamado al compromiso histórico que tienen los gobiernos y el sistema educativo desde las aulas para enfrentar la exclusión educativa y social que ha afectado a los afrodescendientes, indígenas y comunidad LGBTI, con el fin de unir esfuerzos para abordar la problemática desde un colectivo convergente. La educación incluyente no debe ser una realidad alejada, pues es en la escuela en donde se generan espacios adecuados para la formación en valores y principios que contribuyan a garantizar relaciones sociales basadas en el respeto. De allí que el maestro deba ser un líder en la consolidación del proyecto intercultural; su formación como profesional y como persona inciden directamente en el propósito de transformar el sistema educativo mediante estrategias innovadoras que den respuesta a las necesidades de la población diversa presente en las sociedades.

Es importante y necesario aclarar cómo surge el tema de la inclusión educativa, el cual ha sido abordado por entidades y pactos internacionales que en vista de la situación crítica del acceso y calidad de la educación para las personas con alguna discapacidad física o cognitiva, requerían medidas urgentes para enfrentar esta situación. Sin embargo, este enfoque se fue ampliando no solo a personas con algún tipo de discapacidad sino a los menos favorecidos: minorías étnicas, poblaciones inmigrantes, y a aquellos excluidos de la educación (Díaz y Franco, 2010).

Cabe retomar aquí la conceptualización de la Unesco (2005) frente a la inclusión educativa:

Es un proceso de abordaje y respuesta a la diversidad de las necesidades de todos los alumnos a través de la creciente participación en el aprendizaje, las culturas y las comunidades, y de la reducción de la exclusión dentro y desde la educación. Implica cambios y modificaciones en los enfoques, las estructuras, las estrategias, con una visión 
común que incluye a todos los niños de la franja etérea adecuada y la convicción de que es responsabilidad del sistema regular educar a todos los niños.

En relación a la anterior conceptualización, la Constitución colombiana de 1991 recoge en su artículo 13 el principio de igualdad con el que busca asegurar el desarrollo integral y adecuado de las personas del territorio sin ningún tipo de discriminación o exclusión:

Todas las personas nacen libres e iguales ante la ley, recibirán la misma protección y trato de las autoridades y gozarán de los mismos derechos, libertades y oportunidades sin ninguna discriminación por razones de sexo, raza, origen nacional o familiar, lengua, religión, opinión política o filosófica.

Por lo anterior, se reconoce que los logros normativos siguen siendo difícilmente materializados en la realidad, esta es una de las razones por las que esta investigación le apuesta a la búsqueda de la consolidación del proyecto intercultural a partir de la dimensión educativa en Latinoamérica y el Caribe, dejando registrado que implica cambios y modificaciones en los enfoques y las tendencias educativas para generar transformaciones estructurales en los currículos de formación de los educadores. En este sentido, es responsabilidad de todos los formadores contribuir con la justicia social. Aquí se deben reconocer los esfuerzos y luchas realizadas por comunidades indígenas y afrodescendientes, en búsqueda de una participación activa en la construcción de modelos educativos incluyentes y en pro de un trato respetuoso y justo entre sujetos diversos.

En relación a la legislación sobre diversidad, Colombia no ha sido la excepción en Latinoamérica; existen leyes y decretos como el Título III de la Ley 115 de 1994, El Decreto 804 de 1995, la Ley 70 de 1993 y el Decreto 1122 de 1998. Esta normatividad que contempla la diversidad cultural en la educación se ha expedido gracias a la lucha de los grupos étnicos del país; sin embargo, siguen siendo pocos los establecimientos educativos que consideran la etnoeducación o la cátedra de Estudios Afrocolombianos en sus Proyectos Educativos Institucionales (PEI) y, por supuesto, en los currículos.

Ahora bien, siendo el Proyecto Educativo Institucional (PEI) un proyecto social marcado especialmente por las relaciones e intereses y la participación de sus actores, se espera que desde allí se construya el mapa de navegación de las instituciones educativas acorde a las metas comunes. Teniendo esto en cuenta, como lo afirma Beltrán et al. (2007), el PEI no está siendo diseñado y adecuado a las necesidades de los grupos poblacionales 
más vulnerables, lo que hace más difícil abordar las prácticas educativas inclusivas. Esta situación hace más compleja la realidad porque, como se ha afirmado anteriormente, no hay cambios significativos en los currículos frente a la multiculturalidad; el proceso de formación e inclusión educativa debe ser continuo para asegurar la calidad y el desarrollo de diálogos equitativos en el espacio escolar.

Las anteriores situaciones ponen en evidencia las falencias que el sistema educativo ha tenido para llevar a cabo procesos de inclusión adecuados en cuanto al trato de la diversidad cultural y en materia de diversidad sexual. No existen tampoco estrategias que aseguren que a los sujetos con preferencia o expresiones sexuales diferentes a la heterosexual, reciban un trato adecuado dentro del sistema escolar. En esta línea, el informe de la Secretaría General de Planeación de Bogotá (2010) -en el que se plasman los resultados de una encuesta a 1213 personas que se autoreconocen como parte de la comunidad LGBTI-, señala en relación al maltrato escolar:

El 30\% de personas expresan haber sido agredidas física y/o psicológicamente en el sistema educativo, el 66.37\% considera que es debido a su OS/EG/IG5. Quienes han sido víctimas de este maltrato en mayor proporción han sido las personas transgeneristas (74.68\%) y en menor proporción los gays (56.27\%). Sin embargo, los porcentajes de agresión por esta causa son superiores al $50 \%$ para todos los casos (p. 26).

De lo anterior se puede inferir que el sistema educativo actual no está preparado para abordar, desde sus principios, enfoques, fundamentos y normatividad, la diversidad que se evidencia en las sociedades y en las aulas. Esto lleva a afirmar que el proceso formativo y la participación del docente desde la escuela es considerada fundamental, porque el docente es un mediador y líder en las transformaciones de la escuela. Precisamente, Beltrán et al. (2007) afirman al respecto: «De ahí que el perfil del docente en el proceso de inclusión se caracterice por participar en redes de trabajo cooperativo y por la transformación de su práctica, convirtiendo el aula en un espacio para fomentar el respeto, el reconocimiento de la diferencia y el trabajo compartido entre los estudiantes» (p. 156).

Por lo anterior, es que esta investigación se orienta hacia la búsqueda de aquellos factores o causas que inciden en la perpetuación de la exclusión de afrodescendientes,

5 Orientación Sexual, Expresiones de Género e Identidad de Género. 
indígenas y comunidad LGBTI, mediante las percepciones de los docentes sobre la importancia de abordar la diversidad cultural y sexual en el aula. Los docentes son agentes transformadores dentro de la escuela, por lo que resulta importante relacionar su labor educativa con sus aportes desde las prácticas pedagógicas en el aula.

Para esta investigación se contó con la participación de 35 docentes de instituciones oficiales y privadas de la ciudad de Bogotá, que mediante una encuesta manifestaron su percepción frente a la problemática de la exclusión de indígenas, afrodescendientes y comunidad LGBTI. Su participación permitió dar respuesta a interrogantes como los siguientes:

- ¿Se considera importarte abordar en el aula temas sobre diversidad cultural y sobre los aportes que los grupos étnicos han hecho a la construcción de nación?

- ¿Qué apreciaciones tienen los docentes respecto a la importancia de impartir en el aula temas sobre diversidad sexual a sus estudiantes?

- ¿Son las escuelas espacios que promueven el adecuado desarrollo entre sujetos culturalmente diversos?

- ¿Son los docentes agentes que promuevan el trato justo a la diversidad cultural y sexual?

Las respuestas a las anteriores preguntas permitieron el acercamiento al objetivo general de la investigación y, así mismo, permitieron establecer los pasos para lograrlo, mediante los siguientes objetivos específicos:

- Establecer mediante la revisión documental y estadística de organismos multilaterales (Unicef, Unesco, Organizaciones Estatales) la situación de los afrodescendientes, indígenas y comunidad LGBTI en la escuela.

- Reconocer, a partir de las percepciones de los docentes, algunas causas que influyen en la exclusión de afrodescendientes, indígenas y comunidad LGBTI en la escuela.

- Proponer algunas recomendaciones, desde la educación intercultural, para enfrentar la exclusión de la diversidad sexual y cultural en la escuela.

Los objetivos mencionados direccionaron las estrategias metodológicas de lainvestigación con el fin de determinar algunos de los factores que inciden en la falta de diálogo, participación y visibilización de afrodescendientes, indígenas y comunidad LGBTI en la escuela. 


\section{Marco de referencia conceptual}

\section{Propuestas conceptuales sobre la educación intercultural.}

Al hablar de diversidad en la escuela uno de sus componentes clave es el cultural, por lo tanto la forma de entender la diversidad va a estar mediada por el concepto de cultura que se tenga. Una de las formas de entender la cultura según Taylor, pionero del concepto, es: «aquel todo complejo que incluye el conocimiento, las creencias, el arte, la moral, el derecho, las costumbres, y cualesquiera otros hábitos y capacidades adquiridos por el hombre» (1975, p. 29). En este sentido la cultura es producida por y para el hombre, por lo que es necesario precisar que no hay una sola y auténtica cultura, pues es una producción del hombre que es diverso, por lo tanto es apropiado hablar en términos de culturas y de diversidad cultural.

Las dimensiones que forman parte de la cultura están vinculadas con las relaciones de poder, y son estas las que definen sus prácticas y concepciones, «la cultura no está en los genes, es algo aprendido» (Restrepo, 2012, p. 25), por lo que su significado responde a discursos que en el caso de las sociedades multiculturales han provenido de élites etnocentristas que han desconocido la participación de determinados grupos humanos en la construcción y significación de la cultura. Por ello, constantemente la multiculturalidad es asumida más como una característica, que como una realidad que define las identidades, relaciones y necesidades de los sujetos.

En esta investigación, la cultura será entendida como un concepto dinámico, el cual representa el conjunto de valores, prácticas, sentidos, relaciones de poder, relaciones con el espacio y la interacción que los sujetos construyen y extienden de generación en generación. En la sociedad hay diversas culturas y expresiones de las mismas, los sujetos producen sentidos y prácticas que son diferentes para cada grupo social, de esta manera si se asumen las sociedades como multiculturales se está diciendo que hay varias formas de expresar, sentir y pensar, que no todos los sujetos de un mismo territorio apuntan hacia las mismas metas y que no todos tienen las mismas necesidades. Lo anterior representa para esta investigación la diversidad cultural.

En este orden de ideas, al considerar la escuela como el escenario donde converge la diversidad cultural, se presenta como un campo de construcción, transmisión y transformación de la cultura y sus representaciones, por lo tanto tiene la responsabilidad de abordar las exclusiones; por esta razón se invita a «tomar conciencia pedagógica de que los 
niños y jóvenes están llamados a vivir como ciudadanos en una sociedad irreversiblemente más global, plural y multicultural» (Jordán, 2005, p. 10).

Por otra parte, frente a las dinámicas de exclusión y marginación que se han perpetuado en el sistema educativo, en relación a su deficiencia para asumir a sujetos culturalmente diversos, la discusión de la interculturalidad pasa a mediar por un aprendizaje que contribuya al diálogo, que sea contextualizado y que responda a las necesidades de los grupos étnicos, tanto mayoritarios como minoritarios y de aquellos sujetos con expresiones diversas; la escuela debe ser propuesta como un potencializador positivo de la diferencia, no como un espacio de exclusión de la misma.

En este contexto, es importante tener claro que, «las identidades se construyen a través de la diferencia, no al margen de ella» (Hall, 2013, p. 18), por lo tanto, si se asume la diferencia desde una connotación negativa, la identidad de aquellos que hablan desde allí será subvalorada e ignorada. Cuando la presencia de diferentes culturas en la escuela suele ser ignorada o tratada superficialmente, se promueve el rechazo y la discriminación de aquellos que, en relación a un grupo mayoritario y homogéneo, se construyen como minoría, y esta es una de las principales problemáticas que las escuelas deben enfrentar en las sociedades multiculturales.

Ahora, sobre el concepto de interculturalidad, específicamente en relación a su concepción, existe multiplicidad de autores que han trabajo al respecto. Uno de ellos es Ruiz (2011), quien la define así:

Una corriente de pensamiento que hace referencia a la interacción entre culturas, de una forma respetuosa, donde se concibe que ningún grupo cultural está por encima del otro, favoreciendo en todo momento la integración y convivencia entre culturas. En las relaciones interculturales se establece una relación basada en el respeto a la diversidad y el enriquecimiento mutuo; sin embargo, no es un proceso exento de conflictos, pues éstos se resuelven mediante el respeto, el diálogo, la escucha mutua, la concentración y la cooperación (p. 2).

Por su parte, Rojas (2005) entiende la interculturalidad de la siguiente manera:

La interculturalidad es un proyecto político, asumido por algunas organizaciones sociales, por educadores y por intelectuales de diversas tradiciones, uno de cuyos propósitos es develar 
las formas en que ha sido históricamente asumida la diferencia cultural y construir nuevas formas de relación entre grupos humanos y sujetos en sociedades multiculturales (p. 2).

Tubino (2005) y Walsh (2010) señalan que la interculturalidad que se evidencia puede ser usada de manera funcional al sistema y en este sentido promueve la marginación. Así mismo, explican cómo este concepto puede llegar a ser también emancipador, ya que este tipo de interculturalidad es uno de los primeros espacios o campos para poner sobre la mesa el debate de la inclusión, por lo menos a nivel normativo; sin embargo, la propuesta apunta hacia el logro de la interculturalidad crítica, pero desde el interior del mismo sistema opresor se pueden dar procesos de emacipación:

La mirada funcional de la interculturalidad reconoce la diversidad cultural pero con miras a la inclusión del sistema hegemónico donde se sigue viendo como subalterna dicha diversidad (2010, p. 78).

En este sentido la interculturalidad se asume como una estrategia de cohesión social, en tanto y en cuanto asimila a los grupos socioculturales subalternizados a la cultura hegemónica (2005, p. 5).

Por otro lado, la interculturalidad crítica considera que «se trata de cuestionar las diferencias y desigualdades construidas a lo largo de la historia entre diferentes grupos socioculturales, étnico-raciales, de género, de orientación sexual, entre otros» (Tubino, 2005, p. 5).

De las anteriores explicaciones se puede inferir que la interculturalidad es un proyecto que contempla todas las dimensiones posibles: políticas, educativas, sociales, culturales, económicas, raciales, éticas, de género, entre otros aspectos, por lo tanto su consolidación es un proceso en construcción. Su principal objetivo y apuesta es asumir que todas las culturas son igualmente válidas y garantes de respeto y participación, por lo tanto, se cuestionan las relaciones de poder que han ocultado y marginado las expresiones, que, en relación a las culturas y los valores hegemónicos, han considerado inferiores otras formas de existencia y pensamiento.

Así las cosas, la interculturalidad es asumida aquí como un proyecto de construcción de diálogos y consensos entre sujetos diversos, superando las jerarquías, exclusiones 
e invisibilizaciones, producto de la herencia monocultural de Occidente. Su objetivo atraviesa todas las dimensiones sociales para consolidarse como un proyecto emancipador en la búsqueda y rescate de experiencias, conocimientos y cosmovisiones de los grupos y sujetos inferiorizados e ignorados.

Por lo anterior, para la consolidación del proyecto intercultural, la escuela representa un lugar y una función determinantes, en cuanto campo de reproducción de los principios culturales dominantes que han visto la otredad desde la subalternización y la exclusión. Por consiguiente, la escuela puede convertirse en uno de los medios para subvertir estas problemáticas, y por ello «la interculturalidad en el marco de la educación es entendida como la formación de habilidades que posibilitan el encuentro con la otredad, sea de forma cultural, género, estrato social o religión diferente a la propia» (Rehaag, 2010, pág. 78).

Por otra parte, como señala Ruíz (2011), «la educación intercultural es la educación centrada en la diferencia y pluralidad cultural más que una educación para los que son culturalmente diferentes. [...] la educación intercultural se opone a la integración entendida como asimilación» (p. 2). Lo anterior implica asumir en el sistema educativo una mirada positiva y de reconocimiento de la otredad, en términos de respeto, tolerancia y comprensión.

La educación intercultural, como propuesta, cuestiona el sistema educativo para dar paso a una interacción en términos de respeto a la otredad o alteridad. La propuesta no va dirigida solamente a los grupos étnicos, esta se orienta a la educación inclusiva donde los menos favorecidos -como los campesinos, mujeres, sujetos de diferente credo u orientación sexual, niños, jóvenes, entre otros- deben forman parte del proyecto intercultural, no como actores integrados que pese a su presencia en la escuela se mantiene la estructura de discriminación o exclusión; para que exista inclusión es necesaria la transformación estructural de instituciones educativas que den respuesta a las políticas que, en materia de inclusión, existen en Latino América y el Caribe. No se puede perder la esperanza de la posibilidad de vivir en un mundo donde todos los hombres se miren como iguales; al respecto, Buganza (2006-2007) afirma que esta es, definitivamente, una utopía vigente.

Así pues, el contexto en el que se desarrolla la educación intercultural está concebido en primera instancia para albergar a todos los individuos, integrando sus aspectos culturales y sociales, sin distinción de lenguas o creencias, permitiendo de esta forma que el beneficio sea para la sociedad de manera global. La interculturalidad contribuye a la construcción y transformación de la identidad de los sujetos, la relación dinámica entre saberes y el encuentro de diversas culturas, asimismo, da al estudiante la oportunidad 
de afirmar, reafirmar o modificar los preceptos que orientan sus identidades, sin discriminación o sesgos; cuando se tiene conocimiento de las múltiples identidades y sus expresiones se posibilita que la identidad individual se consolide y que las relaciones con el otro se transformen.

Para esta investigación, la educación intercultural es un proyecto indispensable para las sociedades multiculturales, es la estrategia política, cultural, social y pedagógica para la erradicación de las formas de exclusión que invisibilizan y niegan la participación de determinados actores en la sociedad. Con este proyecto se reconoce la importancia y existencia de sujetos diversos, con valores, pensamientos y emociones diferentes, que permiten enriquecer la cultura, el conocimiento y las relaciones interpersonales a través de un diálogo que «debe ser abierto, recíproco, crítico y auto-crítico» (Sáez, 20o6, p. 869). Es por ello que no se parte de extraer o separar la etnicidad, el género o la clase social, por ejemplo; la educación intercultural dialoga y discute con los actores que integran la comunidad educativa, vinculándolos a un proceso formativo pertinente y respetuoso del libre desarrollo y expresión, todo ello bajo los valores y principios de la convivencia y los derechos por una justicia social. En este sentido todos los actores hacen parte del proyecto intercultural.

\section{Diseño metodológico}

Esta investigación indagó sobre los posibles factores que inciden en la exclusión de afrodescendientes, indígenas y comunidad LGBTI en la escuela, a partir de las percepciones de los docentes que laboran en instituciones educativas públicas y privadas de la ciudad de Bogotá, asimismo se abordaron los estudios de los organismos multilaterales frente al tema en mención. Para ello, se recurrió en un primer momento a las fuentes estadísticas y documentales que expusieran la situación de la diversidad cultural y sexual en la escuela y, posteriormente, a través de la encuesta aplicada a los docentes, se analizaron sus percepciones sobre los procesos de exclusión de los grupos citados anteriormente. El estudio buscó un acercamiento a los docentes a partir de las experiencias que han tenido a lo largo de su formación y ejercicio de la profesión con relación al trato de la diversidad.

El diseño metodológico asumió la complementariedad de metodologías, haciendo uso de fuentes estadísticas con el fin de contrastar cifras sobre la situación de las poblaciones afrodescendientes, indígenas y LGBTI en el ámbito escolar y, posteriormente, desde el enfoque investigativo cualitativo-interpretativo se analizó la encuesta aplicada a 
los docentes para establecer los posibles factores de la exclusión de afrodescendientes, indígenas y comunidad LGBTI en la escuela.

Cabe aclarar que este análisis no pretende hacer generalizaciones sobre todos los docentes de la ciudad de Bogotá en relación al tema investigado, pues se trata de un estudio de caso, pero sí pretende dar origen a investigaciones futuras sobre temas de diversidad cultural y sexual en la escuela.

Por último, se presentan algunas recomendaciones desde la educación intercultural, como referentes que a juicio de este estudio deben ser considerados para la construcción de diálogos equitativos en el aula.

\section{Resultado de la investigación}

Los resultados de la investigación corresponden al análisis de las percepciones dadas por los 35 docentes de colegios oficiales y privados de la ciudad de Bogotá que participaron en la encuesta. Esta indaga, en primer lugar, por el perfil de los docentes de acuerdo a su formación y, posteriormente, por sus percepciones en relación con la situación de la exclusión de afrodescendientes e indígenas en el aula, junto con su visión en relación a la diversidad sexual y a la preferencia sexual de los estudiantes diferente a la heterosexual.

A continuación se explica cada uno de los aspectos tratados en la encuesta.

\section{Información general de los docentes}

Con el fin de tener una perspectiva amplia sobre las percepciones de los docentes en cuanto a temas de diversidad cultural y sexual, se quiso conocer detalles sobre su formación, el tipo de institución en la que trabajan y el tiempo que llevan ejerciendo su profesión. Esto permitió tener una visión más clara sobre su percepción en cuanto al tema y el porqué de sus respuestas. No se le consultó sobre nombres de las instituciones ya que esto podría comprometer su opinión frente a lo encuestado.

En relación al tipo de institución, la mayoría de los docentes $(62,5 \%$ ) trabajan en escuelas de tipo oficial, su nivel educativo alcanza un $50 \%$ en especialización, un $20 \%$ en estudios de maestría y un $1 \%$ de doctorado, lo que sugiere que cerca del $70 \%$ de los docentes han dado continuidad a su formación profesional. Este dato permite, entonces, 
hacer una relación de la situación en la formación de educación superior de los docentes, en cuanto a temas de diversidad cultural y sexual.

Un $69 \%$ de los encuestados lleva entre 1 y 20 años ejerciendo su labor como docente, lo que permite tener una confiabilidad frente a sus opiniones y frente a los procesos que llevan en las aulas de las instituciones donde laboran. Por lo anterior se les preguntó si en su formación como docentes había estado presente el tema de cómo abordar la diversidad cultural y sexual; el 40\% de los encuestados manifestó haber trabajado tanto la diversidad cultural como la sexual y un 30 \% expuso que no estuvo presente en su formación este tipo de aspectos.

Como se puede inferir, la mayoría de los docentes están formados y capacitados para ejercer su profesión; sin embargo, es preocupante que cerca de un 30\% de ellos no haya tratado en su formación temas relacionados con la diversidad, pues es ya una evidencia de las falencias en el proceso formativo de los docentes de la ciudad. No obstante, pese a dicha falencia, como se verá más adelante, los resultados también revelaron que los docentes consideran importante el tener presente este tipo de realidades para enfrentar las situaciones de discriminación y exclusión en las instituciones educativas.

Para mostrar la problemática de la exclusión de la diversidad cultural y sexual en el contexto educativo se acudió al análisis de la situación en la escuela de la población afrodescendiente, indígena y comunidad LGBTI, ya que han sido grupos afectados por el sistema educativo tradicional. En esta línea, se exponen a continuación los hallazgos, en primer lugar, de la población afrodescendiente e indígena en las instituciones educativas de Bogotá y luego los de la comunidad LGBTI.

\section{La población afrodescendiente e indígena en las instituciones educativas de Bogotá}

La presencia de población afrodescendiente en Colombia, según el último censo (2005), asciende a un $10.6 \%$ aproximadamente; sin embargo, esta cifra sigue siendo debatida, ya que existen problemas como el autoreconocimiento por parte de la comunidad, lo que implicaría que esta cifra puede ser aún mayor. La Editorial Nuevo Siglo señala que «en la ciudad de Bogotá la comunidad negra representa el 1.5\% de la población» (www. elnuevosiglo.com.co) lo que equivale a cerca de 100.00 habitantes, por lo que el sistema educativo no es ajeno a la presencia de afrodescendientes en sus aulas. 
La encuesta revela que un $87 \%$ de los docentes expresa la presencia de población afrodescendiente en las instituciones en que trabajan; es claro que la visibilización y participación de la población afro debe ser abordada en la escuela, ya que muchos de los estudiantes provienen de otras ciudades y contextos diferentes. Si la escuela ignora este tipo de situaciones el desarrollo de la identidad del estudiante se verá limitado por la homogenización cultural que se evidencia en las aulas.

Teniendo en cuenta que los docentes encuestados son parte de colegios de básica primaria y secundaria, los jóvenes son actores fundamentales en los procesos pedagógicos en el aula, así que deberían asumirse como receptores y constructores del conocimiento. Según Asprilla (2014), la población joven indígena y afrocolombiana representa un 49\% de la población total de jóvenes en el país, lo que evidencia la riqueza multicultural de la sociedad colombiana y representa un fenómeno a trabajar dentro de las escuelas.

Cuadro 1. Peso relativo de jóvenes por cada grupo étnico 2005

\begin{tabular}{llll}
\multicolumn{1}{c}{ Grupo étnico } & \multicolumn{1}{c}{ Población total } & \multicolumn{1}{c}{ Población joven } & \% jóvenes \\
\hline Total & $40.602 .551^{*}$ & 9.677855 & 23,84 \\
\hline Indígenas & 1.392 .623 & 337.199 & 24,21 \\
\hline Afro-colombianos & 4.311 .757 & 1.081 .517 & 25,08 \\
\hline Población mayoritaria & 34.898 .171 & 8.259 .139 & 23,67 \\
\hline${ }^{*}$ El total incluye la población que dio respuesta a la pregunta de autorreconocimiento. \\
\hline
\end{tabular}

Fuente: Asprilla, 2014.

El mismo informe señala el nivel educativo alcanzado según la pertenencia étnica; de los 1.081.517 que representan la población joven afrocolombiana un 42 \% culmina la básica secundaria, de los 1.392.623 jóvenes indígenas un 9\% llega a finalizar la secundaria. Lo anterior contrasta con las cifras de la población mayoritaria (la que considera que no tiene pertenencia étnica), pues de sus cerca de 8 millones de jóvenes aproximadamente el $40 \%$ logra culminar sus estudios secundarios.

Estas cifras empiezan a evidenciar un panorama general en términos de acceso y permanencia. La población afrocolombiana tiene altos niveles de permanencia y acceso según el informe. En relación a la población indígena, la situación es más compleja ya que sus modelos educativos no alcanzan a incidir en el sector urbano. El Espectador señala que «según datos del Censo de Población DANE 2005, la población indígena en Bogotá asciende 
a 15.032 personas, cifra a la que se le debe añadir los 6.379 indígenas que se encuentran en situación de desplazamiento, de acuerdo a lo reconocido por la Agencia Presidencial Acción Social» (www.elespectador.com). Aunque en la ciudad ellos representen un o,33\% de la población total, su situación no debe ser ignorada; esto en relación a la permanencia y acceso a la educación representa un problema ya que no existe una visibilización de los indígenas, de su historia y su cultura, imposibilitando el diálogo entre culturas.

Los docentes encuestados señalan que no existe presencia indígena en sus instituciones $(58,3 \%)$, lo que refleja la situación comentada anteriormente. Otro factor que es importante analizar es el ambiente escolar de inclusión y participación de afrodescendientes e indígenas, es decir, analizar cómo es el trato dentro de los establecimientos educativos para ellos y qué dificultades o fortalezas existen; en diálogos con docentes, por ejemplo, algunos estudiantes indígenas expresan que se sienten incómodos con sus apellidos y ocultan su origen por temor a burlas.

En el cuestionario se les pidió a los docentes que evaluaran la calidad de las relaciones entre sujetos afrodescendientes y no afrodescendientes e indígenas y no indígenas, en los siguientes gráficos ${ }^{6}$ se muestran sus respuestas.

Gráfico 1. Relación entre población indígena y población no indígena

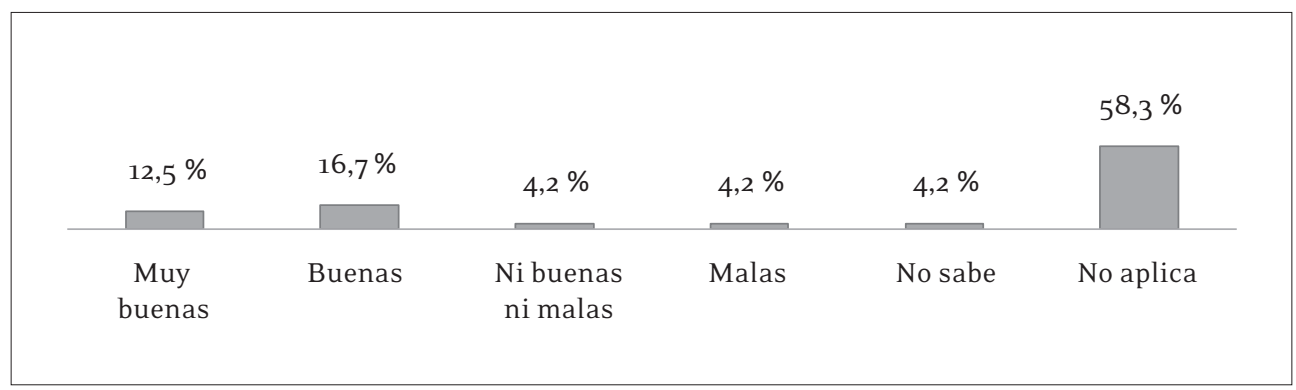

6 La opción «No Aplica» de los gráficos corresponde a los docentes que señalaron que no tenían presencia de población afro o indígena en sus instituciones. 


\section{Gráfico n. ${ }^{0}$ 2. Relación entre población afrodescendiente y población no afrodescendiente}

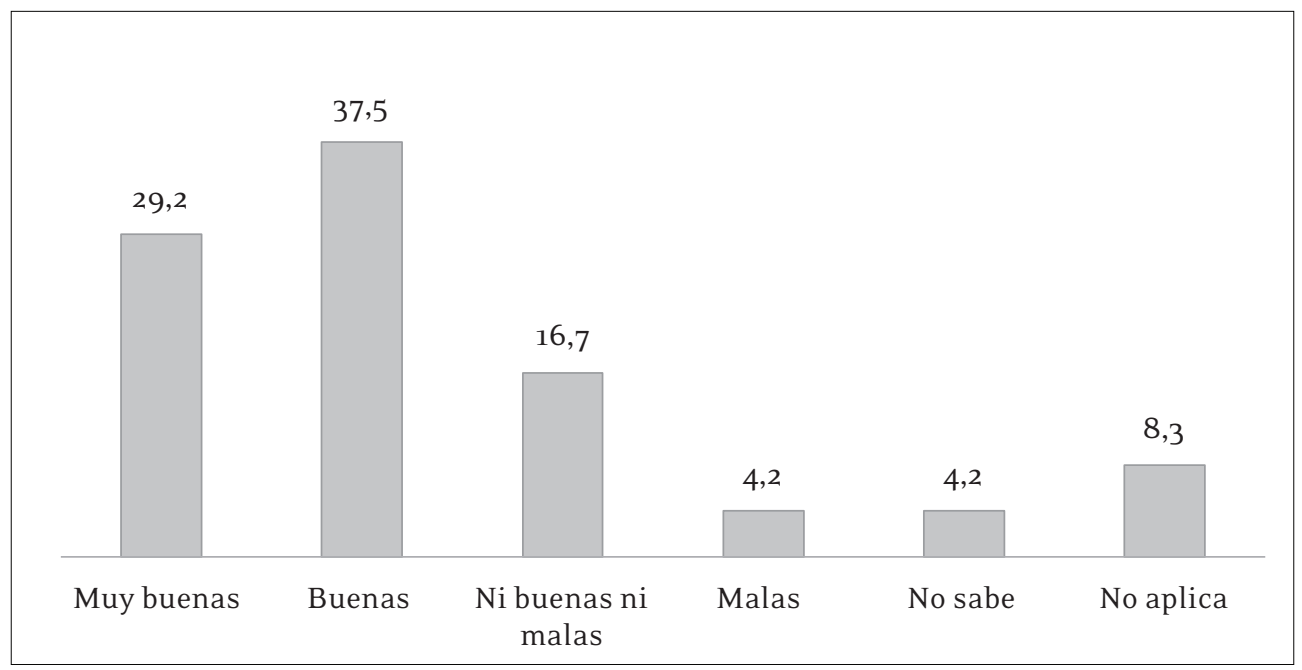

Del primer gráfico, se puede inferir que el $29 \%$ de profesores que señaló que existía presencia indígena, señaló que las relaciones son positivas dentro de la institución. Asimismo, para la población afrodescendiente cerca de un $66 \%$ apunta hacia la misma situación favorable en la institución. Sin embargo, frente a esta pregunta se indagó posteriormente por la existencia de casos de discriminación en la institución; a los encuestados se les pidió señalar si conocían situaciones en las que se burlen de la manera de actuar, vestir o hablar de indígenas o afrodescendientes, y de contestar de manera afirmativa, señalar con qué frecuencia se presentaban estas situaciones. Los resultados se muestran a continuación:

Cuadro $n .{ }^{\circ}{ }_{2}$

\begin{tabular}{lccc}
\hline & \multicolumn{2}{c}{ Burla indígenas } & \multicolumn{2}{c}{ Burla afrodescendientes } \\
\hline & $\%$ & & $\%$ \\
\hline Sí & 8,3 & Sí & 33,3 \\
\hline No & 25,0 & No & 45,8 \\
\hline No Aplica & 66,7 & No aplica & 12,5 \\
\hline
\end{tabular}


Gráfico n. ${ }^{\circ} 4$. Frecuencia de situaciones de burla

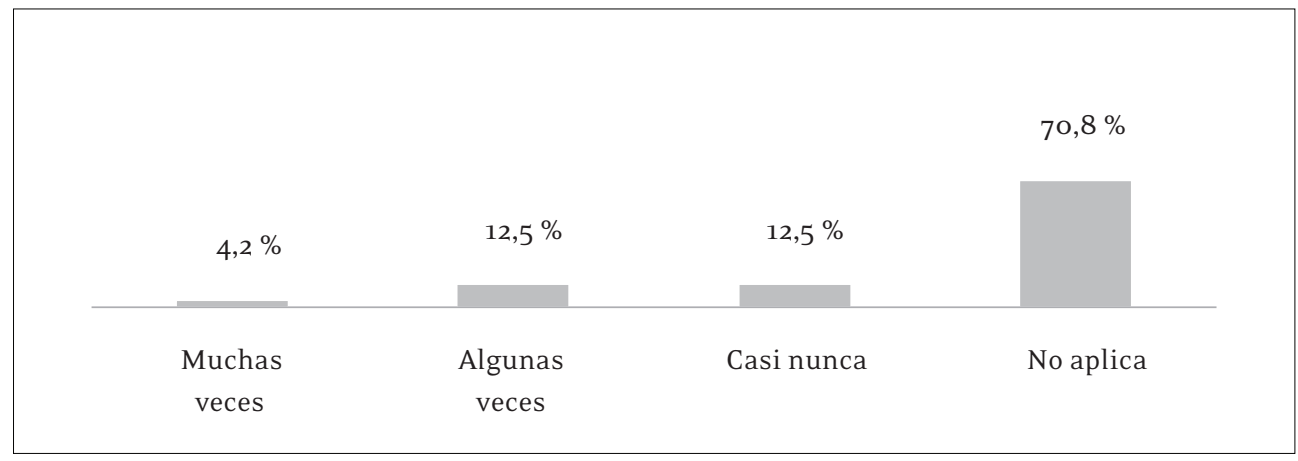

La información revela que en el caso de los afrodescendientes las situaciones de discriminación son más representativas que en el caso de los indígenas; esta problemática sigue siendo parte de las demandas por parte de la población afrodescendiente que sigue siendo víctima de actos de discriminación racial. Un informe sobre el racismo en la escuela de la Alcaldía Mayor de Bogotá, La Secretaría de Educación (SED) y la Agencia Española de Cooperación Internacional (Aecidi) (2009, p. 74) brinda los siguientes datos:

Gráfico $n .{ }^{0} 5$. Víctimas del racismo y la discriminación racial en la escuela

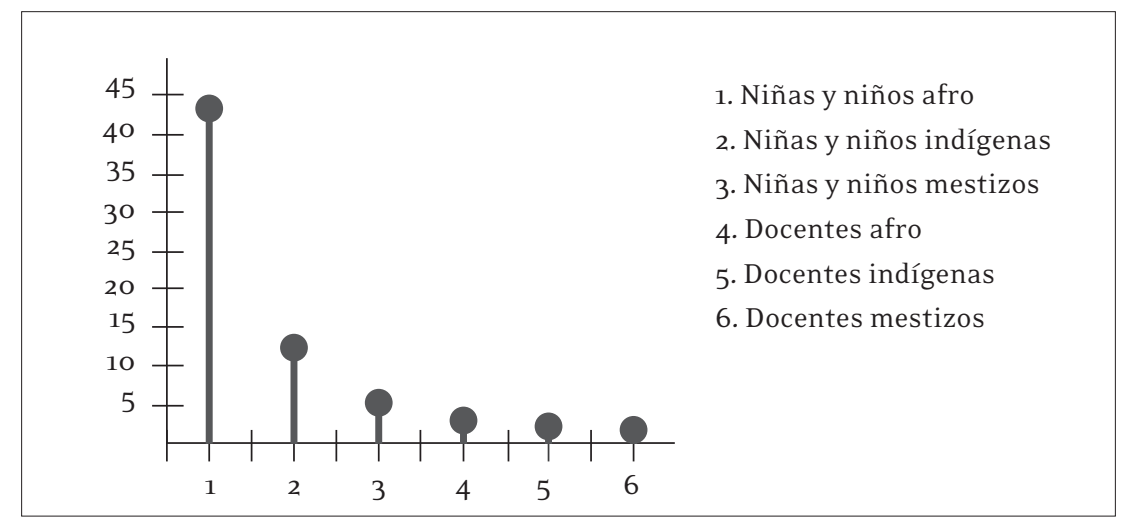

Fuente: Alcaldía Mayor de Bogotá, Secretaría de Educación y Agencia Española de Cooperación Internacional (2009) 
El estudio fue realizado mediante una encuesta a docentes de instituciones distritales de la ciudad de Bogotá e indica que, tal y como puede verse en la gráfica, cerca de un $45 \%$ de los niños y niñas afros son víctimas de discriminación; a ellos les sigue la población indígena en el segundo lugar. Si bien no constituyen la población con mayor número de estudiantes en las escuelas de Bogotá, estas cifras estarían apuntando a que los pocos que se encuentran en las escuelas de la ciudad están siendo víctimas de abusos por su origen étnico, dentro de la misma institución.

Es importante anotar que el que los docentes señalen, cuando se les pregunta por la frecuencia en que se evidencian casos de discriminación, que no existen problemas significativos, puede deberse a que el docente, aunque haya presenciado eventos en que los estudiantes afrodescendientes o indígenas hayan sido afectados, no esté a favor de los actos de discriminación. Incluso, es probable que el docente no sea consciente de que algo tan común como llamar a un estudiante afrodescendiente negro o negrito, sea también una manera de propiciar burlas y actos de exclusión.

Sobre este tema, también se les preguntó a los docentes si frente a las situaciones de discriminación en la institución se tomaban medidas para prevenir y enfrentar estos casos. Un 41,7 \% señaló que sí se tomaban medidas para enfrentar abusos contra población afrodescendiente e indígena; sin embargo, un 30\% señaló que no se tomaban medidas al respecto, situación que revela la gran problemática de las escuelas para implementar estrategias contra la discriminación. Lo anterior puede indicar la falta de temas dentro del currículo sobre la diversidad cultural y, asimismo, que la formación en valores es clave y debe hacer parte de una propuesta de educación intercultural incluyente.

En el aspecto curricular, es importante tener en cuenta la formación de los docentes, el conocimiento o información que tienen sobre nuevas propuestas pedagógicas y si consideran importante o no aplicar dichas propuestas. Por ello, se les preguntó si tenían conocimiento sobre propuestas que han sido pensadas para el trato de la diversidad en las escuelas, sus respuestas se muestran en el gráfico n. ${ }^{\circ} 6$.

Como se puede observar, la información sobre las propuestas pedagógicas nombradas no alcanza a superar el $25 \%$, lo que evidencia una formación insuficiente de los docentes para abordar temas de diversidad cultural. Pese a que ellos señalaron que en su formación habían visto esta temática, el conocimiento que tienen sobre las propuestas que se están implementando a nivel nacional en este campo es poco. No obstante, cabe mencionar que los docentes señalaron, con un $62 \%$, que han aplicado algunas de las propuestas en las instituciones y que en su currículo sí aplican temas afrodescendientes (54\%) e indígenas 
Gráfico n. ${ }^{\circ}$ 6. Información sobre propuestas pedagógicas

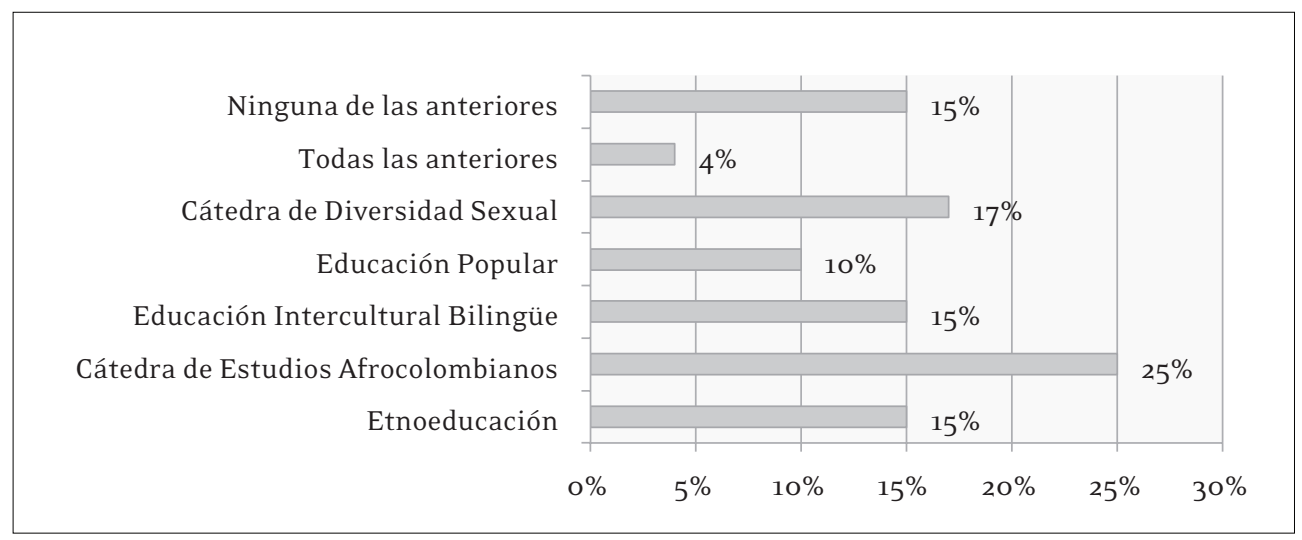

(41\%). Es importante cuestionarse sobre los temas y modelos que emplean los docentes para incluir temas sobre grupos étnicos en el aula, ya que, por ejemplo, no se trata solo de celebrar o folclorizar las tradiciones de dichos grupos, sino que la propuesta es ir más allá e incorporar temas que realmente amplíen el conocimiento sobre su cultura y cosmovisión.

Finalmente, pese a la falta de formación e información frente a las estrategias pedagógicas que apoyan un trato respetuoso a la diversidad cultural, los docentes manifiestan en la encuesta la importancia de incluir y trabajar desde las instituciones estos temas. El $95 \%$ de los docentes señala la importancia de abordar la diversidad cultural y manifiestan tener buenas relaciones con afrodescendientes y grupos indígenas. Esto representa la potencialidad de poder trabajar con los docentes temas de diversidad cultural, ya que pese a que en su formación existan debilidades al respecto ellos reconocen la importancia de abordar estos temas en el espacio escolar.

En suma, la situación de la población indígena y afrodescendiente es problemática ya que siguen estando en situación de vulnerabilidad, invisibilidad y exclusión. Generar un cambio requiere de un trabajo constante de todas las estructuras sociales y de la escuela como medio para la aproximación al diálogo intercultural. La importancia de trabajar estos aspectos desde la academia reside en el alcance del rol del docente, no solo como difusor y constructor de conocimiento, sino como socializador de principios éticos y morales en la relación entre los sujetos. Si se trabaja en este aspecto, indígenas y afrodescendientes serán actores con mayor reconocimiento y participación dentro de las estructuras sociales y se promoverá así un diálogo equitativo y necesario en el conjunto social. 


\section{Diversidad sexual: Opinión de los docentes en relación a la comunidad LGBTI en la escuela.}

El tema y rastreo de la situación de aquellas personas que se identifican como parte de la comunidad LGBTI es complejo, ya que sigue siendo una temática difícil de abordar pese a la luchas que esta comunidad ha emprendido en pro de sus derechos como personas y ciudadanos, por lo que encontrar cifras de autorreconocimiento y en la escuela es aún más complejo.

El informe de la Secretaría de Planeación Distrital de Bogotá (2010) expone algunas cifras sobre la situación de la comunidad LGBTI en relación a la visibilización de las personas que deciden hacer pública su orientación sexual o de género:

El $44.36 \%$ de las lesbianas, el $53.9 \%$ de los gays y el $73.16 \%$ de las y los bisexuales lo hacen con amigos y amigas. Le sigue para lesbianas y gays contarle a la mamá para el $31.28 \%$ y el $31.63 \%$ respectivamente; y a la pareja con el $20.63 \%$ para los y las bisexuales. Por su parte la población transgenerista en un $42.68 \%$ le cuenta a todo el mundo y a sus hermanas y hermanos en un $45.15 \%$. Es de señalar que quien le cuenta a su pareja en mayor proporción son los bisexuales, en un $20.63 \%$. Los gays son quienes más le cuentan al personal de salud y a personas en su trabajo (en un $10.07 \%$ y un $11.33 \%$ respectivamente). Quienes en menor proporción prefieren decirle a nadie están las personas bisexuales, en $4.15 \%$ y las lesbianas en un $4.36 \%$ (p. 20).

Como se puede inferir, las cifras no contemplan a los docentes o la comunidad educativa como público para expresar las preferencias sexuales o de género. El informe señala que las principales razones para no hacer pública la orientación sexual o de género es el temor al rechazo por parte de sus familias, amigos o compañeros de trabajo; por ello, algunas personas asumen esta faceta de su vida como algo privado e íntimo que no necesita ser contado. Esto dificulta el identificar dentro del aula a aquellos sujetos que tengan una orientación sexual o de género diferente a la heterosexual.

Sin embargo, más del 50\% de los docentes encuestados señala que conoce estudiantes con preferencia sexual diferente a la heterosexual; aunque estos docentes no indican cómo lograron identificarlos, es claro que las aulas son escenarios donde se visibilizan estas otras sexualidades, de allí que la escuela se enfrente al reto de cómo abordar y asegurar a estos estudiantes una educación digna y respetuosa de su personalidad. 
En el ámbito escolar, los niveles de escolaridad de las personas de la comunidad LGBTI son positivos. El informe señala que lesbianas, bisexuales y gays cuentan con cerca de un $60 \%$ en el logro del nivel universitario; sin embargo, las personas transgeneristas alcanzan como mayor logro el nivel secundario. Esto evidencia que pese a que es difícil acceder a cifras sobre el autorreconocimiento de personas que se consideren parte de la comunidad, las escuelas no son escenarios ajenos a la presencia de lesbianas, gays, bisexuales o transgeneristas, y en ese sentido la importancia, tanto para personas de la comunidad como para las ajenas, de abordar en la escuela temas de diversidad sexual es fundamental para fomentar relaciones de respeto entre unos y otros.

La diversidad sexual en la escuela sigue siendo motivo de debate; las cifras de discriminación señalan que la población LGBTI ha presenciado situaciones de discriminación en un $90 \%$ y un 54 \% lo atribuyen a su orientación sexual o expresión de género; el sistema educativo no está exento de estas situaciones, los transgeneristas $(74,68 \%)$ y los gays $(56,27 \%)$ son los que en su mayoría han señalado ser víctimas de discriminación o rechazo (Alcaldía Mayor de Bogotá, Secretaría Distrital de Planeación, 2010). Estas cifras concuerdan con los datos obtenidos de la encuesta realizada, ya que un 50\% de los docentes señaló que sí ha presenciado burlas a los estudiantes gays, mientras que sobre los estudiantes transgeneristas los encuestados señalan que no existe presencia de ellos en su institución.

Los docentes encuestados reconocen la importancia de incluir temas sobre diversidad sexual en las escuelas; un 83 \% afirmó que es necesario abordar en las aulas estas temáticas, aunque consideran que la responsabilidad de educar a los estudiantes sobre este tema no solo recae en las instituciones educativas (como se puede ver en el gráfico n. ${ }^{\circ}$ ), pues si bien es un tema que se puede considerar privado y difícil de tratar, los padres de familia son aquí actores fundamentales para abordarlo y efectivamente se requiere no solo de las escuelas para lograr un trato adecuado del tema.

Pese a la importancia que los docentes dan al tratamiento de este tema en la escuela, en los currículos de sus instituciones difícilmente se tratan temáticas al respecto; un $62 \%$ de los docentes negó la existencia de contenidos sobre diversidad sexual. A nivel distritral, este debate ha generado varias controversias; en el año 2012 la concejal Clara Lucía Sandoval señaló que el dar cátedras sobre diversidad sexual en la escuela sin autorización de los padres era algo inadecuado y que promovía la homosexualidad (Mojica Patiño, 2014). Pensamientos como este dificultan que la Secretaría de Educación Distrital pueda implementar este tipo de cátedra, sin contar con la carga académica y la falta de tiempo y recursos para hacerlo. 


\section{Gráfico n. ${ }^{0} 7$. Responsabilidad sobre diversidad sexual}

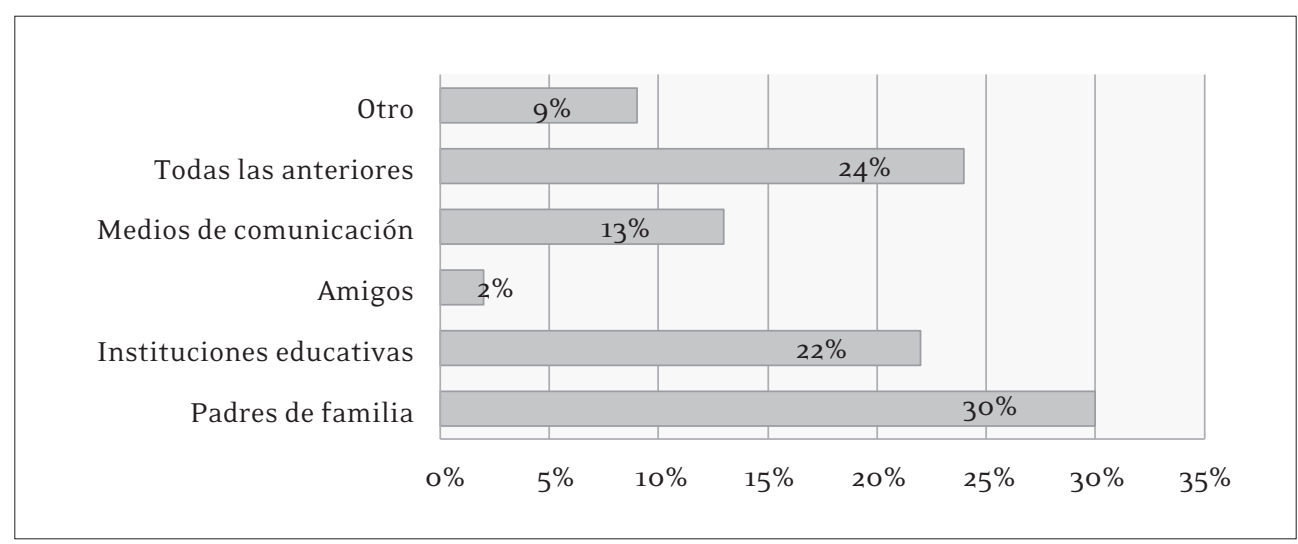

Otro aspecto a considerar es la predisposición de los docentes para abordar este tema; en el cuestionario se les preguntó por su relación con aquellos estudiantes con preferencia sexual o expresiones de género, en este caso con los estudiantes gays que son los que evidencian presencia en la institución, sus respuestas están plasmadas en el siguiente gráfico:

\section{Gráfico n. ${ }^{0}$ 8. Relación Docente/Estudiante gay}

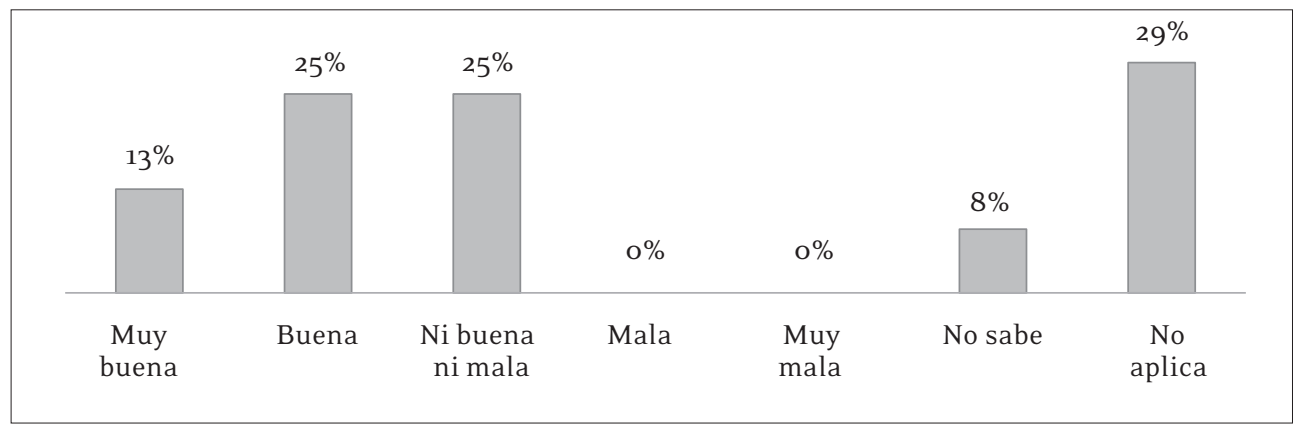

Establecer cómo son las relaciones entre los estudiantes gays y los docentes requiere de un análisis más profundo; sin embargo, el panorama general apunta a que las relaciones no son problemáticas, lo que indica que la predisposición de los docentes para abordar temas sobre la diversidad puede llegar a ser positiva. Al respecto, los docentes señalan que tanto los colegios como ellos mismos son agentes que promueven la inclusión y visibilización 
de la diversidad cultural y sexual, pero aún sigue siendo débil la materialización de sus propósitos y la problemática de abordar temas de género y sexualidad continua siendo un asunto complejo debido a las concepciones que se tienen en general frente al tema.

En suma, la situación de los estudiantes que hacen parte o que se identifican como parte de la comunidad LGBTI debe ser tenida en cuenta, ya que las cifras de discriminación a esta población son significativas. Pese a que los docentes consideran importante abordar el tema, en su formación y en los colegios no se ha profundizado en las estrategias metodológicas que permitan un acercamiento mucho más adecuado a este tema. La propuesta desde la educación intercultural le apuesta a que las expresiones de género de los sujetos sean tenidas en cuenta en las escuelas, ya que este espacio debe ser un lugar de respeto y de consolidación de relaciones entre los sujetos, sin prejuicios o agresiones. En este sentido, encaminar proyectos para este logro es una necesidad de nuestro sistema educativo.

\section{Conclusiones y recomendaciones}

El reconocimiento de la multiculturalidad como componente y realidad de las sociedades requiere de la transformación de las estructuras y principios que sustentan las relaciones entre los sujetos. En el ámbito escolar, dicha transformación se hace necesaria; la inclusión pasa a ser un aspecto a considerar ya que la diversidad que se presencia en las aulas requiere de un conocimiento libre de jerarquías y monoculturalismos.

Cuando se reconoce que los sujetos se expresan, se conciben, se configuran y tienen necesidades diferentes según su cultura o su identidad, se afectan los propósitos de la escuela como agente socializador, cuyo deber deja de ser solo el conocimiento y su labor pasa a tener implicaciones éticas y morales frente a la inclusión y participación de los sujetos en todas sus áreas y espacios. Lo anterior permite la construcción de la educación intercultural como un proyecto emancipador y constructor de nuevas relaciones sociales basadas en el respeto y participación de aquel concebido como otro ser diferente, que se materializan cuando uno se concibe diferente al otro y en esa medida es capaz de reconocerlo también diferente, así como cuando se establece un diálogo respetuoso desde las diferencias.

En esta investigación se lograron determinar algunos factores que afectan la construcción de relaciones interculturales en las escuelas, entendiendo que estas 
corresponden a un diálogo justo y equitativo entre sujetos diversos, al margen de estereotipos y exclusiones. Por ello es importante considerar lo siguiente:

- La falta de un currículo, en la formación docente, que incluya temas sobre la diversidad cultural y de género es un aspecto que afecta la labor pedagógica en las aulas; si el docente no cuenta con la formación para abordar situaciones de discriminación, se dificulta el reconocimiento y respeto de los estudiantes entre personas diversas. Respecto a las estrategias pedagógicas (CEA, Etnoeducación, Cátedra de diversidad sexual) que han surgido en Colombia como respuesta a las necesidades de aquellos que han sido excluidos, los docentes no cuentan con la formación e información suficiente. Asimismo, las instituciones que ejecutan estas propuestas desde la política pública tienen poco apoyo y visibilidad.

- Pese a que los docentes señalan la importancia de abordar la diversidad cultural en la escuela, las situaciones de discriminación tanto para afrodescendientes como para indígenas continúan: los indígenas, por ejemplo, han sido desplazados de diferentes regiones del país y su integración al sistema educativo distrital sigue siendo difícil, lo que puede deberse a factores como la diferencia entre su lenguaje nativo y el español, o la situación de pobreza que algunos indígenas se encuentran al llegar a la ciudad de Bogotá.

- Respecto al currículo, el porcentaje señalado por los docentes en la inclusión de temas afrodescendientes e indígenas en el aula es bajo; teniendo en cuenta la falta de formación e información del docente sobre estas temáticas, difícilmente los temas abordados van a llevar a la ruptura de paradigmas y estereotipos que se tienen de estas comunidades.

- Sobre la diversidad sexual, esta constituye un tema difícil de abordar debido a que afecta y es parte de una dimensión íntima de las personas. En las escuelas ha sido difícil incluir estos temas en los currículos, como lo muestra la encuesta y los informes consultados - cabe resaltar aquí que contar con estadísticas frente a la población LGBTI es complejo-, a esto se le suma la situación de esta población en el sistema educativo, la cual, según el informe referenciado, es complicada ya que las cifras de discriminación son significativamente altas. Por otra parte, este es un asunto que los docentes no pretenden abordar solos desde las aulas, los padres de familia y los medios de comunicación son actores que también se consideran parte fundamental del proceso; sin embargo, es importante orientar a los estudiantes en el desarrollo de su sexualidad y de la comprensión de las múltiples expresiones de la misma. 
Los factores generales identificados en este estudio representan un problema complejo, ya que el construir procesos de interculturalidad y diálogo en la escuela requiere de cambios graduales que demandan esfuerzos para que la política pública no se quede escrita y la formación de docentes sea coherente con dicha política. Sin embargo, no se trata solamente de la formación de los docentes, también se requiere implicar a otros actores sociales, pues las instituciones educativas son solo uno de los tantos lugares de socialización de los sujetos, así que la familia, los medios de comunicación, entre otros, son agentes que deben involucrarse en el proceso del trato de la diversidad.

La investigación logró identificar potencialidades, como el hecho de que los docentes encuestados reconocen la importancia de abordar en la escuela temas sobre diversidad cultural y sexual, pues este es uno de los primeros pasos para concienciar a las instituciones educativas sobre la importancia de estos enfoques. Es importante aclarar que aquí no se propone un absolutismo donde la escuela solo se enfoque en temas étnicos o sobre diversidad sexual; el lograr un equilibrio y complementariedad en los currículos escolares es un proceso difícil y aquí se reconoce dicha problemática. Lo que sí se pretende es propiciar el debate sobre las estrategias que lograrían dicho objetivo, por ello al encuestar a los docentes no solo se buscó identificar problemáticas, sino motivar el interés de los mismos por los temas mencionados.

La importancia de aproximarse a la construcción del proyecto intercultural radica no solo en asegurar que las sociedades sean interculturales mediante la construcción de políticas y normativas (interculturalidad funcional); el proyecto intercultural va más allá pues busca transformar la estructura misma del sistema educativo, sus diseños curriculares y procesos pedagógicos, metodológicos, y, en general, los conocimientos y prácticas que allí se construyen. Por lo anterior, un primer logro, por ejemplo, no es asegurar solo el acceso al sistema educativo, sino trabajar en un ambiente escolar y pedagógico que asegure el desarrollo de las identidades del sujeto acorde a sus particularidades étnicas, de género o credo.

Para alcanzar este logro, es importante comprender que la ausencia de los temas sobre diversidad cultural e interculturalidad en los currículos de formación de los docentes en Colombia es una situación compleja que debe contrarrestarse: estos temas deben formar parte de los planes de estudio así como han sido asumidos desde hace décadas en los países europeos. Asimismo, las instituciones educativas deben generar estrategias o mecanismos para el acceso a las propuestas pedagógicas -que tanto el Ministerio de Educación Nacional (MEN) como los grupos sociales han implementado para mejorar las prácticas 
pedagógicas- e incorporar en el PEI y los currículos los elementos y conocimientos necesarios para alcanzar una educación inclusiva.

Por último, es importante hacer énfasis en que la apuesta por la educación intercultural se toma aquí como una estrategia con gran potencial, ya que sus premisas son pertinentes para las sociedades multiculturales que se han visto afectadas por la exclusión y la marginación de aquel considerado diferente e inferior. Cuando se abordan estas problemáticas desde la escuela, se da paso a subvertir los estereotipos que han sido parte de la configuración de la diversidad. De este modo, se hace posible y se asegura que los estudiantes puedan crear sus identidades y ver las de otros sin ningún tipo de representaciones falsas, lo que da paso a relaciones y diálogos críticos, autocríticos y respetuosos que contribuyen a erradicar las formas de discriminación y a permitir que cada sujeto se reconozca y valore las múltiples formas de conocer y ser que existen en nuestra sociedad multicultural.

\section{Referencias}

Alcaldía Mayor de Bogotá, Secretaría Distrital de Planeación. (2010). Bogotá: Ciudad de Estadísticas. Lesbianas, gays, bisexuales y transgeneristas en cifras. Bogotá.

Asprilla, J. (Febrero de 2014). Censo 2005 Jóvenes afro-colombianos: Caracterización sociodemográficas y Aspectos de la Migración Interna. Recuperado de: http://www.dane.gov.co/ files/censo2005/etnia/sys/jovenes_afrocolombianos.pdf

Beltrán, L., Bedoya, K., Benítez, C., Carmona, L., Castaño, C., Castro, L., y otros. (2007). Formación docente: Una propuesta para promover prácticas pedagógicas inclusivas. Revista Educación y Pedagogía, 19(47).

Buganza, J. (2006). La otredad o alteridad en el descubrimietno de América y la vigencia de la Utopía Lascasiana. Razón y Palabra, (sp).

Castro Suárez, C. (2009). Estudios sobre educación intercultural en Colombia: Tendencias y perspectivas. Memorias.

Colombia. (1991). Constitución Política de Colombia. Recuperado de: http://www.procuraduria.gov.co/ guiamp/media/file/Macroproceso\%2oDisciplinario/Constitucion_Politica_de_Colombia.htm

Díaz, O., y Franco, F. (2010). Percepción y actitudes hacia la inclusión educativa de los docentes de Soledad, Atlántico. En Revista del Instituto de Estudios en Educaicón Universidad del Norte, 12-39. 
El Espectador. (2010). Recuperado de: http://www.elespectador.com/articulo-212347-bogota-vivenmas-de-630o-indigenas-desplazados-violencia

El nuevo siglo. (2012). Recuperado de: http://www.elnuevosiglo.com.co/articulos/6-2012-bogot \% $3 \%$ A1-tiene-10oooo-afrocolombianos.html

Ferrão Candau, V. M. (2010). Educación intercultural en América Latina: Distintas concepciones y Tensiones actuales. En Estudios Pedagógicos, 36(2), 333-342.

González, J. E. (2007). Ciudadanía e Interculturalidad. En González, J. E. Ciudadanía y Cultura. Bogotá: Universidad Nacional de Colombia.

Hall, S. (2013). Introducción: ¿quién necesita 'identidad'? En Hall, S. y Dugay, P., Cuestiones de identidad cultural, (pp. 13-39). Buenos Aires: Amorrortu.

Hirmas Ready, C. (2009). Educar en la diversidad cultural: Aprendizajes desde la experiencia innovadora en América Latina. En Revisata Latinoamericana de Educación Inclusiva 3(2), 91 -108.

Jordán, J. A. (2005). ¿Que educación intercultural para nuestra escuela? Barcelona: Universidad Autónoma de Barcelona.

Mojica Patiño, J. A. (2014). El Tiempo. Recuperado de http://www.eltiempo.com/vida-de-hoy/ educacion/ARTICULO-WEB-NEW_NOTA_INTERIOR-11022004.html

Rehaag, I. (2010). La perspectiva intercultural en la educación. En El Cotidiano, (160), 75-83.

Restrepo, E. (2012). La cultura en la imaginación antropológica. En E. Restrepo, Intervenciones en teoría cultural (pp. 21-53). Popayán, Colombia: Universidad del Cauca.

Rojas, A (2005), Inclusión social, interculturalidad y educación. ¿Una relación (im) posible?, Grupo de Trabajo Flape Colombia Inclusión Social, Interculturalidad y Educación, UPN (sp).

Rojas, A. (2008). ¿Etnoeducación o Educación Intercultural?. Estudio de caso sobre la licenciautra en Etnoeducación de la Universidad del Cauca. En D. Mato, Diversidad cultural e interculturalidad en Educación Superior. Experiencias en América Latina (pp. 233-243). Caracas: IESALC-UNESCO.

Ruíz, A. (2011). Trabajar la Interculturalidad en Educación Infantil. Recuperado de http://www.csi-csif. es/andalucia/modules/mod_ense/revista/pdf/Numero_38/ANA\%2oRUIZ\%2oORTEGA_2.pdf

Ruíz, O. A. (2011). Innovación y Experiencias Educativas. Recuperado el 2014, de http://www.csi-csif. es/andalucia/modules/mod_ense/revista/pdf/Numero_38/ANA\%2oRUIZ\%2oORTEGA_2.pdf

Sáez, R. (2006). La educación intercultural. En Revista de Educación, 859-881.

SED, AECID. (2009). Investigando el racismo y la discriminación racial en la escuela. Colombia. Alcaldía Mayor de Bogotá.

SITEAL. (2012). La situación educativa de la población indígena y afrodescendiente en América Latina. Argentina: Unesco-OEI.

Taylor, E. (1975). La ciencia de la cultura. Barcelona: Anagrama. 
Tubino, F. (2005). La interculturalidad crítica como proyecto ético-político. Encuentro continental de educadores agustinos. Lima, Perú: http://oala.villanova.edu/congresos/educacion/limaponen-02.html.

Unesco. (2012). Situación educativa de América Latina y el Caribe. Recuperado de http://www.orealc. cl/educacionpost2015/wp-content/blogs.dir/19/files_mf/efainformefinaldef57.pdf

Walsh, C. (2010). Interculturalidad crítica y educación intercultural. En Viaña, J., Tapia L., y Walsh C., Construyendo interculturalidad crítica (pp. 75-96). La paz, Bolivia, Instituto Internacional de Integración del Convenio Andrés Bello. 